\title{
Retraction Note to: Cadmium permeates through calcium channels and activates transcriptomic complexity in wheat roots in response to cadmium stress
}

\author{
Jieyu Yue ${ }^{1} \cdot$ Xin Zhang ${ }^{1} \cdot$ Ning Liu $^{2}$ \\ Published online: 2 May 2018 \\ (c) The Genetics Society of Korea and Springer Science+Business Media B.V., part of Springer Nature 2018
}

\section{Retraction to: Genes \& Genomics (2017) 39:183-196 https://doi.org/10.1007/s13258-016-0488-1}

The authors are retracting this article [1] because Figs. 1A, $1 \mathrm{E}$ and $1 \mathrm{~F}$ have been taken without permission from the Master's thesis of Qiaoling Wang, "The mechanism of Cd stress on the physiological and cytotoxicity of onion seedlings" submitted to the College of Life Sciences, Tianjin
Normal University in April 2014. All authors agree to this retraction.

\section{Reference}

1. Yue J, Zhang X, Liu N (2017) Genes Genom 39:183. https://doi. org/10.1007/s13258-016-0488-1

The original article can be found online at https://doi.org/10.1007/ s13258-016-0488-1.

Jieyu Yue

yueshan1982@163.com

Xin Zhang

xiaohan81@163.com

Ning Liu

xioaohan81@163.com

1 Tianjin Key Laboratory of Animal and Plant

Resistance, Tianjin Normal University, Tianjin 300387,

People's Republic of China

2 Yantai Entry-Exit Inspection and Quarantine Bureau, Yantai 300387, People's Republic of China 